\title{
Enunciación
}

http://revistas.udistrital.edu.co/ojs/index.php/enunc

DOI: http://dx.doi.org/10.14483/udistrital.jour.enunc.2016.1.a07

enunciación

Artículo de reflexión

\section{Un género discursivo mediático: el defensor del televidente}

\section{A media discursive genre: The defender of the viewer}

\author{
Víctor Alfonso Barragán Escarpeta ${ }^{1}$ \\ Para citar este artículo: Barragán, V.A. (2016). Un género discursivo mediático: el defensor del televidente. Enunciación, 21(1),
} 108-122.

Recibido: 30-abril-2016 / Aprobado: 31-mayo-2016

\section{Resumen}

En este artículo se exponen los avances de la investigación en curso, que tiene como objeto caracterizar el género discursivo mediático a partir de los programas del "defensor del televidente", para evidenciar con ello cómo categorías propias del análisis de los géneros discursivos permiten describir el funcionamiento de prácticas discursivas, en este caso mediática. Esta investigación parte de las ideas de Bajtin (1982), Carranza (2012) así como de la perspectiva sociocomunicativa de Charaudeau (2012) sobre los géneros, ya que brindan elementos teórico-empíricos para el establecimiento de dicha caracterización, y de igual forma, al ser perspectivas que enfatizan en el componente social de los textos, permiten la comprensión de variantes como las relaciones entre los participantes y la influencia de estas en el discurso. Para ello, con la metodología se plantea el análisis de dos programas de diferentes cadenas de televisión pública, a través de la realización de transcripciones e imágenes, seleccionados a partir del establecimiento de las siguientes categorías: ámbito de práctica social, situación global de comunicación (SGC) y situación específica de comunicación (SEC); también las propiedades discursivasy formales; los marcos flexibles y el sujeto agente.
De esta manera, se realiza un ejercicio teórico-práctico de índole inductiva que rescata cómo las categorías de la situación comunicativa y el análisis de elementos como los soportes permiten mayor profundización de diferentes dimensiones de las prácticas discursivas mediáticas (las relaciones sociales, las temáticas, etc.) así como observar en qué medida hablamos de géneros y subgéneros discursivos en la vida cotidiana.

Palabras clave: discurso, mediación de la comunicación, medios audiovisuales, televidentes.

\begin{abstract}
The following article presents the progress of the research called "A media discursive genre: The defender of the viewer" and has the objective to characterize this particular genre. This research is based on the ideas of Bajtin (1982), Carranza (2012) as well as Social-Communicative Perspective of Charaudeau (2012) about genres, in the way that they give theoretical and methodological elements to the establishment of this characterization, and, in the same way, for being perspectives that emphasize on the social component of texts, let us
\end{abstract}

1 Estudiante de pregrado del proyecto de Licenciatura en Educación Básica con Énfasis en Humanidades y Lengua Castellana, de la Universidad Distrital Francisco José de Caldas (UDFJC), además es miembro del semillero Hermeneia. Correo electrónico: vabarragane@ correo.udistrital.edu.co 
to understand aspects such as relations between participants and the influence of these in discourse. To do this, our methodology analyzes two different programs of public television channels through making transcripts and images, selected from the establishment of the following categories: the field of social practice, the overall situation of communication (SGC) and the specific situation of communication (SEC); also discursive properties and the formal properties; flexible frameworks and the subject agent.In this way, this article makes a

\section{INTRODUCCIÓN}

Ante la búsqueda infructuosa de análisis teórico-empíricos acerca de este tipo de programas, se han encontrado solo opiniones presentadas en columnas periodísticas y comentarios en la web. Con este panorama, creemos que a partir de nuestro objetivo principal -hallar las regularidades y particularidades del discurso del defensor del televidente desde la categoría de género discursivo-, nos será posible conocer las dinámicas de estos programas así como reflexionar sobre sus contenidos.

Por tanto, el presente escrito en un primer momento busca contextualizar estos programas y ofrecer una mirada al estudio de los géneros discursivos, para luego, a partir de la metodología planteada, realizar un ejercicio práctico y empírico que considere los planteamientos teóricos precisos. Estos, de los cuales se tomaron las categorías, pretenden resaltar los estudios más recientes sobre los géneros y se organizan de acuerdo con unos objetivos específicos: así se adoptó el concepto de situación comunicativa de Charaudeau (2012) para definir el género discursivo mediático, el subgénero del discurso del defensor del televidente, también la interacción entre los participantes. Por otro lado se tomaron los postulados de Isolda Carranza (2012) para identificar la relación entre el sujeto discursivo y el género, y entre subgéneros de diferentes ámbitos sociales. Por último, se recopilan algunas conclusiones preliminares. practical-theoretical exercise of an inductive nature which rescues how categories of the communicative situation and the analysis of elements such as supports allow a greater deepening of different dimensions in the media discursive practices (social relation, themes, etc.) as well as observing to what extent we are talking about discursive genders and sub genders in daily life.

Keywords: discourse, communication mediation, audiovisual media, viewers.

\section{LOS MEDIOS DE COMUNICACIÓN Y EL DISCURSO TELEVISIVO}

¿Qué es la televisión? Según Zerillo et al. (2012), es un tipo de medio de comunicación masiva, cuyos elementos estructuran el conocimiento de las personas y, en consecuencia, su concepción general del mundo, conciben la producción discursiva televisiva como una práctica social, donde un emisor envía un mensaje o contenido a múltiples receptores, a través de un canal, mediante un código dado por el contexto de programación. Por ende, para estos autores, la TV contribuye a proporcionar marcos de experiencias en el televidente, que según Guidens (1982, citado por Zerillo et al., 2012) ordenan la experiencia del mundo y los modos como el individuo interpreta.

La televisión es inicialmente un soporte mediático, entendido este como aquel que cumple la función de dispositivo mediante el cual se manifiesta el texto y, por ende, el género. Para Zerillo et al. (2012), "el texto es la materia significante en que el género se enviste" (p. 12). Entonces se entiende que un texto no es un género discursivo, pero sí es parte constitutiva de este, ya que en el texto se manifiesta el género. Para cualquier análisis de este tipo, el estudio de los rasgos distintivos de los géneros solo puede ser observado en el texto. Así texto y género se presentan simultáneamente.

Estos autores indican que, considerada en su conjunto, la TV contiene unidades de comunicación 
dotadas de cierta autonomía, donde (Orza, 2001, citado por Zerillo et al., 2012) hay un ente productor que elabora un texto a partir de unos objetivos y de un lenguaje audiovisual, dirigido a determinadas audiencias. Entonces, estas unidades de comunicación

[...] son los programas, la programación por franjas horarias, toda la programación de una cadena de TV. De esta manera la programación televisiva es un sistema de discursos y está determinada por unos perfiles generales de contenidos, estilos, estructuras internas y formas de funcionamiento comunicativo (Zerillo et al., 2012, p. 43).

Desde este punto, el programa del defensor del televidente viene a ser una unidad de comunicación menor del discurso televisivo, cuya autonomía para establecer sus sistemas discursivos y sus formas de funcionamiento parten de temas controvertidos de discusión con el televidente. Igualmente, al pertenecer a una cadena de programas de un canal, contiene una franja espacio-temporal determinada, en este caso los programas del defensor escogidos se transmiten los días sábados:

- En la mañana, 7:00 a.m. a 7:30 a.m.: Doble vía (Canal Caracol).

- En la tarde, 3:30 p.m. a 4:00 p.m.: Capsula de la justicia (Canal CityTV).

\section{LA PROBLEMÁTICA DE LOS GÉNEROS DISCURSIVOS Y LA BÚSQUEDA DE UN MÉTODO DE CLASIFICACIÓN}

La discusión acerca de los géneros discursivos tiene una amplia historia que siempre apunta a reconocer una búsqueda de métodos que permitan una clasificación tipológica de los diferentes discursos que integran la praxis humana. De esta manera existen clasificaciones iniciales como aquellos de la antigüedad: por un lado, los géneros literarios, que como afirman Calsamiglia y Tusón (2001) comprendía a los géneros mayores, como el lírico-poético, el épico-narrativo y el dramático-teatral, cuya clasificación no basta para establecer una taxonomía general, ya que se enmarca en el ámbito literario, excluyendo aquellos pertenecientes a otros campos de la praxis. Al respecto Charaudeau (2012) afirma:

[...] en el ámbito de la poética, es siempre la singularidad del texto lo que se persigue, tanto por parte del escritor como del analista. El género literario no es más que una reconstrucción a posterior, mientras que, en el ámbito no literario, el género es una necesidad primaria puesto que el hablante se construye como sujeto en ese marco (p. 21).

Por consiguiente, los criterios literarios por el mismo hecho de su especificidad no son suficientes para una clasificación general. En continuidad con el contexto de la antigüedad, se encuentran los géneros retóricos que comprenden el judicial, el político y el epidíctico, aunque la clasificación aún es muy específica, se rescatan dos aspectos:

En este campo ya se ha prestado mayor atención a la naturaleza verbal de los géneros en cuanto enunciados, a tales momentos como, por ejemplo, la actitud con respecto al oyente y su influencia en el enunciado, a la conclusión verbal especifica del enunciado (Bajtin, 1982, p. 246).

Aquí se resalta la intención del hablante a la hora de componer un enunciado en una determinada interacción. El otro aspecto se refiere a la consideración de los ámbitos de la vida institucional de los discursos, según Calsamiglia y Tusón (2001) esto genera unas consideraciones metodológicas importantes:

Considerar el ámbito en el que se produce un género determinado implica tomar en consideración las finalidades, los actores, los temas propios de ese ámbito, y en consecuencia, las formas verbales y no verbales propias o adecuadas para cada caso (p. 253).

Ante la especificidad de estas clasificaciones, durante gran parte del siglo XX se ha estudiado en auge el tema de los géneros, inicialmente desde la perspectiva de la lingüística general, que involucra los 
estructuralistas, los behavioristas y los seguidores de Vossleer, que como rescata Bajtin (1982) su poca atención hacia la consideración del enunciado solo se ha limitado a lo especifico del habla cotidiana; por lo mismo, este autor conceptualiza ampliamente el género:

En cualquier esfera existen y se aplican sus propios géneros, que responden a las condiciones específicas de una esfera dada; a los géneros les corresponden diferentes estilos. Una función determinada (científica, técnica, periodística, oficial, cotidiana) y unas condiciones determinadas, específicas para cada esfera de la comunicación discursiva, generan determinados géneros, es decir, unos tipos temáticos, composiciones y estilísticos de enunciados determinados y relativamente estables (Bajtin, 1982, p. 249).

Aquí el género es tomado como unos tipos de enunciados relativamente prototípicos (debido al gran papel que ocupa el hablante en el cambio de los géneros), compuestos por una estructura, estilos y temas determinados, cuya función y uso están ligados tanto a las condiciones específicas de la esfera social ${ }^{2}$ a la que pertenecen como a las condiciones de los participantes. Además, la gran variabilidad de géneros se determina por la diversidad de las condiciones de la praxis: "[...] la situación discursiva, la posición social y las relaciones personales entre los participantes de la comunicación" (pp. 265-266). Por tanto, es válido considerarlos "correas de transmisión entre la historia de la sociedad y la historia de la lengua" (Bajtin, 1982, p. 251).

A partir de esta consigna, Bajtin realiza una clasificación: los géneros discursivos simples y los complejos. Los primeros obedecen a lo cotidiano y a la comunicación inmediata, como el diálogo coloquial. Por el contrario, a los segundos les corresponden un carácter ideológico, pertenecen a

2 La doctora Dora Inés Calderón (2003) resume que la esfera social (o de comunicación discursiva) para Bajtin consiste en aquellas que se producen a partir de contextos y prácticas sociales, que determinan el espacio de construcción semiótico-social de lo verbal, los roles, los participantes y su interacción. una comunicación más desarrollada y organizada, es decir, más institucionalizada.

Según Calderón (2003), Bajtin para esta clasificación, considera unos criterios metodológicos específicos, como la esfera social, los participantes y sus relaciones, el momento de interacción y las condiciones del enunciado:

[...] esta clasificación obedece a tres criterios: (i) el nivel de relación que tienen los interlocutores con el contexto: inmediato o mediato; (ii) el nivel de elaboración discursiva de los interlocutores; (iii) las condiciones sociales, temáticas y discursivas de la esfera (Calderón, 2003, p. 47).

A pesar de los grandes aportes e importantes aclaraciones, la tipificación de la teoría bajtiniana es débil puesto que, según Charaudeau (2012), los criterios de delimitación no son los suficientemente específicos sino más bien amplios, lo que en consecuencia ocasiona una delimitación frágil entre los diferentes géneros. Por supuesto, en ningún momento negamos la importancia de esta teoría, pero ante las necesidades de nuestra investigación, se hace necesario un método mucho más específico que el bajtiniano; por esto, se adoptó la consigna conceptual y metodológica establecida en la propuesta de situación comunicativa para definir el género.

\section{La situación comunicativa}

Charaudeau (2012), parte de varios postulados bajtinianos y reformula otros, para exponer el método de la situación comunicativa que se caracteriza por identificar tres niveles de análisis en la formación y definición de un género discursivo: el situacional, el de las propiedades discursivas (modos de organización del discurso, modos de tematización) y el formal (léxico, sintaxis, materialidad de la interacción, propiedades textuales y paratextuales). Igualmente, considerando el lenguaje en su uso social y en interacción, el autor identifica el nivel situacional como el inicio de la caracterización, a su vez tiene en cuenta tres 
importantes categorías para este nivel: el ámbito de la práctica social, la situación global de comunicación (SGC) y la situación específica de comunicación (SEC).

Aunque la preocupación por el ámbito de la práctica social como fundamento para comprender los géneros se remonta a Bajtin, Charaudeau (2012) asume el ámbito de práctica social como un comienzo del proceso de comprensión del género que condiciona, en parte, las cualidades del género; en otras palabras, instaura ciertas regularidades discursivas y del comportamiento comunicativo, las cuales son puntos de referencia para el hablante que le permite la interacción verbal. Aun así esta categoría no es suficiente para caracterizar el género, por tanto el nivel situacional también lo constituyen las categorías de situación global de comunicación (SGC) y de situación específica de comunicación (SEC) que terminan por estructurar el ámbito de práctica social.

Charaudeau (2012) denomina la SGC como aqueIla que se realiza a través de dispositivos conceptuales que se encuentran en la comunicación o ámbito de interacción comunicacional. "Es aquí donde los actores sociales se constituyen en instancias de comunicación, alrededor de un dispositivo que determina su identidad, la (las) finalidad(es) que se instaura(n) entre ellas y el ámbito temático que constituye su basamento semántico" (Charaudeau, 2012, p. 31).

En esta categoría es posible determinar el género discursivo al que pertenece el ámbito de la práctica social. Por otro lado, considerado como el lugar de los dispositivos materiales de la comunicación, la SEC es aquella en la que se logra conocer con exactitud:

[...] los interlocutores con una identidad social y roles comunicacionales bien precisos. Así mismo la finalidad del intercambio se encuentra precisada en función de las circunstancias materiales concretas en las que el mismo se realiza [...], concierne tanto a la materialidad del sistema semiológico (gráfico, fonético, icónico, visual, gestual, etc.), como a la situación de intercambio (monolocutiva o interlocutiva) y también a la del soporte de transmisión (Charaudeau, 2012, p. $32)$.
La interacción entre SGC y la SEC, donde la primera se concreta o se materializa en las especificidades de la situación comunicativa, permite señalar que el anclaje social de un género se identifica por estas dos categorías; a partir de estas es probable delimitar qué es un género y dónde se encuentra (en este caso es en la SGC) e igualmente definir qué es un subgénero y dónde se encuentra (en este caso es en la SEC). A partir de este método, Charaudeau (2012) replantea la concepción de género, aunque muy acorde con el planteamiento bajtiniano, como aquel que une un ejercicio de lenguaje e instituye unas formas de interacción de acuerdo con una situación comunicativa determinada, y define los subgénero como aquellos que: "[...] se constituyen por características propias de cada situación específica; las mismas conforman entonces distintos tipos de variantes en el interior de una misma situación global (dentro del mismo ámbito de práctica social) $)^{\prime \prime}$ (p. 34).

\section{Interacción entre géneros y el sujeto agente}

Carranza (2012), tras centrarse en los géneros como marcos flexibles de posibilidades y restricciones sociodiscursivas, sustenta que en las diferentes actividades sociales no utilizamos necesariamente un solo género; todo lo contrario, realizamos un ejercicio constante de posibilidades combinatorias entre aspectos de diferentes géneros. De esta manera, surgen múltiples formas de combinación:

[...] contamos con abundante evidencia acerca de las formas de combinación de géneros, ya sea por incrustación ya sea por alternancia a modo de contrapunto, y acerca de las formas de hibridación de géneros en fusiones que generan configuraciones nuevas (Carranza, 2012, pp. 102-103).

Brevemente: la incrustación acontece cuando un género toma elementos del otro para concretar una intención, o también cuando un género amplio incorpora en menor grado otro género: la alternancia consiste cuando se toman dos géneros que en

2 Cursiva por fuera del texto original. 
ejercicio se ven delimitados y el sujeto alterna entre uno y otro para configurar su discurso; por último, la hibridación se da cuando dos géneros se funden en uno solo y no es posible delimitarlos.

Este ejercicio flexible de la estructura de los géneros solo puede ser concebido considerando los interlocutores como sujetos agentes: según Carranza (2012) es sujeto en cuanto agente social condicionado por la posición social que también depende de la situación para articular su discurso; y agente porque el interlocutor tiene múltiples posibilidades como elegir el género, utilizar algunos elementos en menor o mayor grado, según sus necesidades, etc.

La visión del sujeto agente permite comprender que la responsabilidad de que los géneros cambien, se modifiquen y desaparezcan con el tiempo corresponde al ejercicio de los participantes y de las condiciones sociales. Esta mirada de Carranza permite comprender el cambio y la relación contante de los géneros en las prácticas sociales.

\section{METODOLOGÍA}

Inicialmente, la investigación integra datos de carácter cualitativos ya que se parte del método del análisis del discurso en interacción, desde Kerbrat Orechionni (1986) cuyo esquema permite considerar el ejercicio discursivo subjetivo del sujeto así como la importancia de la influencia de la situación comunicativa. Así se establece el siguiente esquema metodológico:

En primer lugar, los participantes que integran esta interacción y próximos a ser examinados: por un lado aquellos que pertenecen al desarrollo del programa, como los presentadores, quienes en últimas ejercen el papel de defensores y quienes dinamizan el discurso mediático. Por otro lado se encuentran las audiencias o televidentes.

También los instrumentos a emplear, que en este caso lo conforman las transcripciones de unas grabaciones de los diferentes programas (tomadas de la web) de un canal nacional y otro regional, realizadas entre marzo y abril del presente año. El conjunto de transcripciones es:

- Transcripción \# 1: emisión del 18 de agosto de 2015, Caracol (canal nacional).

- Transcripción \# 2: emisión del 2 de julio de 2014), CityTV (canal regional).

- Transcripción \# 3: emisión del 6 de noviembre de 2014, CityTV.

Dichas transcripciones constituyen la primera propuesta del tratamiento de los datos, planteada por Calsamiglia y Tusón (2001), cuyos códigos de transcripción prioriza la gestión de turnos, pero este esquema se modificó brevemente con la integración de otros elementos necesarios.

Otro instrumento es un conjunto de imágenes que evidencian los soportes de comunicación en interacción, así como imágenes guías recopiladas.

Así mismo, se tuvieron en cuenta las categorías tomadas del plano teórico, principalmente los elementos pertenecientes a la situación comunicativa, como: el ámbito de práctica social, la situación global y específica de la comunicación, además del nivel de las propiedades discursivas y el nivel formal. Estas categorías de Charaudeau (2012) brindan un modelo de análisis para la caracterización del género discursivo, el discurso, los participantes y de las características propias de los programas del defensor del televidente. Se emplean, igualmente, categorías del modelo de Carranza (2012) desde la sociología de la práctica: los marcos flexibles y el sujeto agente, que ayudan a visualizar la relación entre subgéneros en el ámbito mediático así como ampliar el ejercicio discursivo de los participantes.

Las unidades que permitirán el ejercicio de dichas categorías la integran: el análisis de las secuencias textuales, para la caracterización del nivel discursivo y el nivel formal; el análisis de los soportes de la comunicación, para caracterizar la interacción de los participantes y los mismos participantes; las transcripciones, para el análisis de las temáticas. 


\section{ANÁLISIS}

\section{El nivel situacional}

Si se parte del análisis situacional, se observa, en principio, que el defensor del televidente se instaura en el ámbito de la práctica de lo mediático, ya que la producción discursiva se realiza en el plano de los medios de comunicación televisivos.

Ahora bien, en el caso de la estructuración del nivel situacional, se encuentra que la SGC del defensor la constituye el dispositivo conceptual de información mediática, ya que se presenta una dinámica de contenidos interpretados y relacionados con el ejercicio de los mass media, el género propio de este dispositivo es el género del discurso mediático. En la caracterización de la SGC del ámbito mediático, Charaudeau (2012) ejemplifica que este "presenta una instancia de información, una instancia de público" (p. 31).

Entonces, el dispositivo mediático contiene, por un lado, la instancia de información, pues esta socializa un contenido anteriormente interpretado; y por otro, la instancia del público, al que le concierne recibir el contenido socializado por la instancia de información.

Las identidades de los participantes se establece en términos de posición o roles lingüísticos: “[...] de acuerdo con la posición de las instancias en el dispositivo y en relación con la finalidad, la cual se define en términos de objetivos discursivos" (Charaudeau, 2012, p. 31). Es decir, primero hay que definir las finalidades del dispositivo. En este caso, comprende en primer lugar el objetivo de información, pues busca instaurar una relación de hacer saber, ya que el programa expone unos contenidos (en su mayoría polémicos) dirigidos a las audiencias; un segundo objetivo discursivo, la demostración, puesto que se busca una versión de verdad acerca de un panorama temático en discusión (la responsabilidad del canal con la publicidad, por ejemplo); y finalmente el objetivo de incitación, para concretar la intención de convencer sobre la veracidad del contenido, y así, asegurar la aprobación de las dinámicas del programa.

Por tanto, es posible notar cómo se forman las identidades: primero, un rol que desde su carácter institucional busca el objetivo de informar, contextualizar y de poner en debate la controversia de un contenido a un público; un segundo rol que recibe la información, participa y es incitado.

El ámbito temático lo constituyen contenidos referentes a la programación y función de los canales de televisión, de esta manera los temas son diversos pero están relacionados con un carácter social y mediático. Así se encuentran temas como la publicidad, la inclusión, la discriminación, etc., que generan un debate del público acerca del cómo el canal los involucra en sus contenidos.

En lo anterior se observa un carácter generalizador de la situación de comunicación del defensor del televidente, ahora se encuentra, desde Charaudeau (2012), cómo lo global se concreta en lo específico. Considerado como el lugar de los dispositivos materiales de la comunicación, la situación específica precisa, en primera instancia, la identidad y el rol de los interlocutores, así como la finalidad (dadas por las circunstancias materiales concretas).

Así, el primer interlocutor es la figura del defensor. Se caracteriza por ser un periodista o participante del canal al cual pertenece el programa, que introduce un tema polémico y la organización de su discurso intenta contextualizar al televidente, para lo cual también se apoya, en el caso de Doble vía, en un periodista que ayuda a dinamizar el programa e invitar al televidente a participar en este espacio. Aunque esto último solo se da al final de los programas. Para ilustrar, los fragmentos de la transcripción \# $1^{4}$ evidencian esta

4 Considerar los siguientes códigos para todas las transcripciones, excepto los participantes ya que son los respectivos a la transcripción \# 1):

a) Las cifras a la izquierda del texto indican el número de toma de palabra.

b) Las mayúsculas iniciales identifican a los participantes: D: defensora del televidente.

$\mathrm{P}$ : periodista presentadora. EX: experto sobre el tema. EN: entrevistador fuera del set de trasmisión. E: entrevistado 1 del programa cuestionado.

c) I, II, III: indican pausas de diferente duración.

d) ?:entonación interrogativa.

e) : alargamiento silábico.

f) -:truncamiento.

g) []: solapamiento.

h) ==:indica que no existe pausa entre una toma de palabra y la anterior.

i) "'": lectura de cartas perteneciente a televidentes. 
secuencia alrededor de un tema, de la siguiente manera: primero, introduce el tema, en este caso el contenido poco profundo de Taggeados (programa cuestionado), y contextualiza a la audiencia apoyándose en videos que resaltan la polémica:

16. P: se estrenó el programa Taggeadosl y como era de esperarse I hubo varios comentarios I algunos jóvenes les pareció excelente I porque habló I de sus problemas y situaciones con su lenguaje I y en su contraste están las cartas de los adultos bastante críticos.

Luego se dinamiza el tema por la lectura de una carta (intervención 20) con la posición del público y la consulta mediante entrevistas (intervenciones 26-27,) a los responsables de los contenidos debatidos como los actores del programa (intervención 27), todo acompañado de intervenciones por parte del defensor (intervención 21):

20. P: Karen Alejandra Mendosa nos dice en su carta I "me parece un programa muy malo I ya que no aporta nada al televidente I pensé que iba a ser un programa diferente que dejara más cosas I pero la verdad me desilusionó I solo muestra temas vacíos I creo que los jóvenes I necesitamos programas con más calidad I y con temas I más interesantes"

21. D: == revisé detalladamente el programa Taggeadosly encontré aspectos muy interesantes I primero I utiliza un lenguaje visual y oral moderno, claro y directo I donde los protagonistas son jóvenes con sus problemas y temáticas I que muchas veces no conocen los padres de familia I ni los adultos I y es desde la óptica de los jóvenes I adolescentes que debemos verlos I pocos programas tienen las moralejas y los buenos ejemplos I que nos dejaron el fin de semana pasado.

26. EN: los padres siempre se preocupan por la enseñanza I o que verán los hijos en un programa II e: ¿qué: puede esperar el televidente en ese sentido?

27. E: ==bueno definitivamente I es un trabajo que venimos e: cocinando desde hace dos años I así que fuimos muy cuidadosos con el contenido Ipero I sin embargo vamos a tratar I temas muy sensibles I en la dinámica familiar I por ejemplo II e: en el primer capítulo vamos a ver como I echan del colegio a los hijos I vamos a hablar de: sexo: I de alcohol I de los temas que tenemos que hablar nosotros los padres...

La figura del defensor asume posiciones dinámicas, ya que hay momentos donde adopta la defensa del televidente, en otras representa el papel de justificación del canal ya sea desde su voz, como por ejemplo la intervención 21, en la que resalta los valores que promueve el programa y ofrece recomendaciones, o también involucrando respuestas directas de los representantes del programa controvertido, es decir, que recurre a instancias de respuesta a las inquietudes (intervención 27).

Por supuesto, esta no es la única secuencia que utilizan todas las emisiones, pero sí la más recurrente, al menos en aquellas que tienen que ver con quejas, inquietudes, sugerencias del público. Hay secuencias que desde el elogio a algún tema, solo se involucran la lectura de este y la reflexión del defensor (anexo 1). CityTV aunque aplica la primera secuencia (con algunas variaciones -por ejemplo, mostrar más entrevistas que cartas-, como se ve en la transcripción \# 2), la discusión de la transmisión solo se centra en un tema específico. Aun así, en rasgos generales todo programa lleva una introducción y contextualización del tema, el debate de los factores positivos y negativos, y finaliza con invitación al público a participar en el programa.

Este primer interlocutor puede verse interpretado de dos formas: por un periodista o persona del canal, como sucede en el Canal Caracol (aparecen defensor y un periodista que nunca contradice las nociones del primero) (figuras 1 y 2). Pero en el canal CityTV el defensor no aparece en persona, en cambio se escucha una narración anónima, figura que no está físicamente pero con la cual se realiza la transmisión (figura 3). 


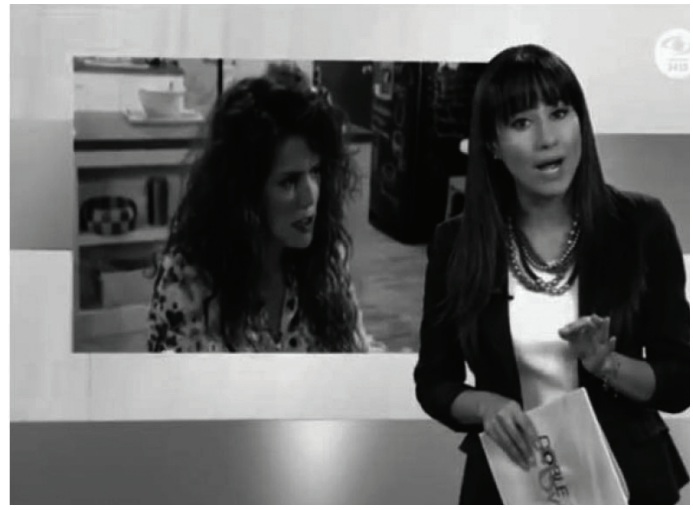

Figura 1. Periodista del Canal Caracol

Fuente: tomado de https://www.youtube.com/watch?v=eL7fFXaOaFE

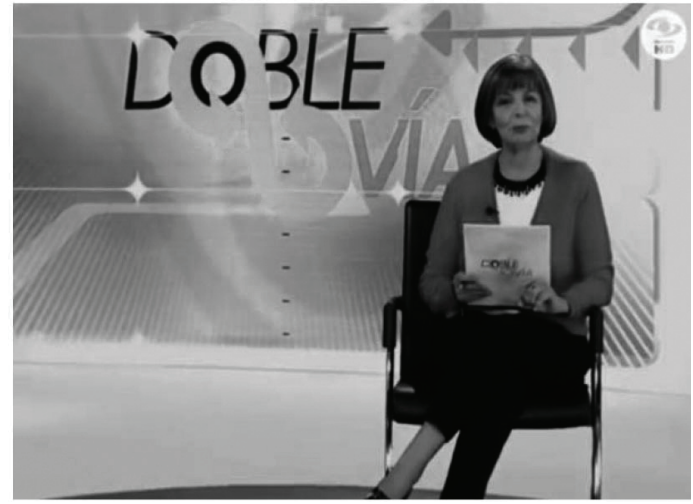

Figura 2. Defensor delCanal Caracol

Fuente: tomado de https://www.youtube.com/watch?v=eL7fFXaOaFE

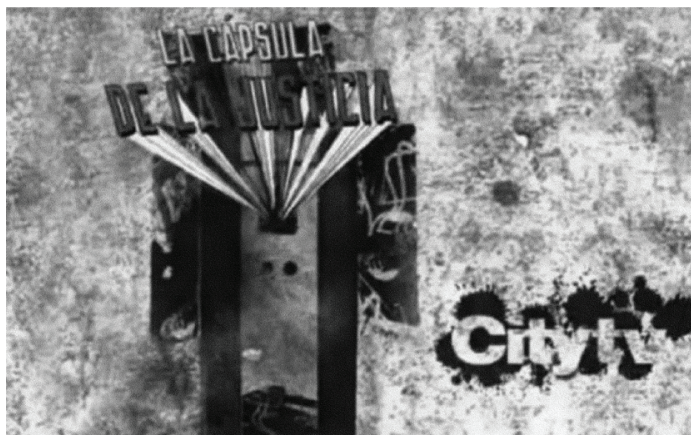

Figura 3. Defensor del Canal CityTV

Fuente: tomado de https://www.youtube.com/watch?v=OYSNS_3r-el

Al observar la figura del defensor, se nota que prevalece el modo enunciativo delocutivo, puesto que se dirige en tercera persona a la audiencia, así como el modo alocutivo al identificarse con la audiencia y con el canal. Las marcas se encuentran en el siguiente fragmento de la transcripción \# 2, considerando: lo subrayado (delocutivo) y los resaltados en cursiva (alocutivo):
3. $\mathrm{D}^{5}$ :la televisión digital terrestre ofrece a la audiencia más canales I mejor calidad en imagen y sonido I y además es gratuita para todos los colombianos I qué deben hacer los televidentes para tenerla en su casa? I cuales son los retos para Citytv? II hoy en la Cápsula de la Justicia analizaremos el tema con expertos I y

5 Defensor de la transcripción \# 2. 
por supuesto con los televidentes II bienvenidos III los expertos nos explicarán de qué se trata la televisión digital terrestre.

44. D: Después de comerciales les contaremos qué deben hacer los televidentes para tener acceso a la televisión digital terrestre I ya regresa I la Cápsula de la Justicia Illcuéntenos lo bueno, lo malo y lo feo de CityTV I juzgue usted mismo y sea fiscal o defensor en la Cápsula de la Justicia ${ }^{6}$.

De otra parte aparece el televidente, segundo interlocutor de la comunicación y quien puede actuar de dos maneras: inicialmente como televidente pasivo, solo recibe la información del programa y programación. La otra actuación se podría denominar televidente crítico, participativo, que con el objeto de dar a conocer su opinión o buscar respuesta recurre al uso de medios para tal propósito, como veremos a continuación.
La situación específica identifica el soporte de intercambio: "El soporte es la materialidad en la que viene soportado el texto -y el género, por supuesto-, es decir, el espacio, medio o dispositivo en que aquel se manifiesta" (Zerillo et al., 2012, p. 11). Por consiguiente, el discurso del defensor del televidente instaura la comunicación a través de la televisión, soporte que permite que el locutor o defensor socialice la información y los temas con el televidente. Por otro lado, aparecen otros dispositivos que instauran la comunicación entre los participantes: la carta electrónica (figuras 4 y 5). A partir de los programas analizados detallamos que la estructura de este tipo de carta se conforma por requerir unos datos particulares del televidente (nombres, documento, edad, residencia), datos de contacto y finalmente el comentario a desarrollar.

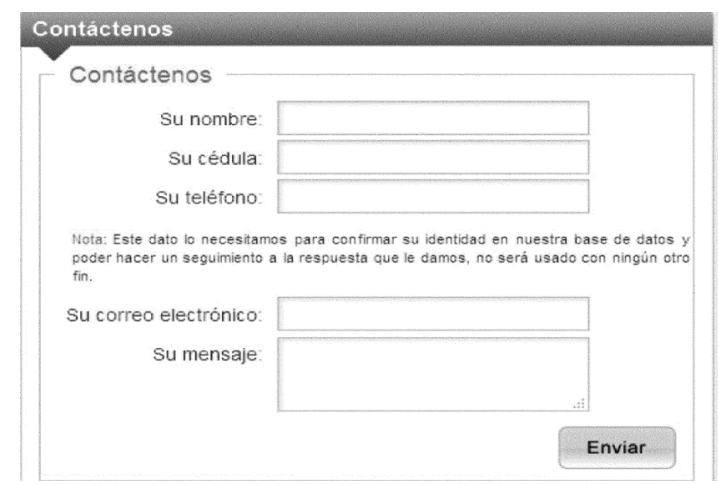

Figura 4. Cápsula de la justicia

Fuente: tomado de Canal CityTV (http://www.citytv.com.co/contacto)

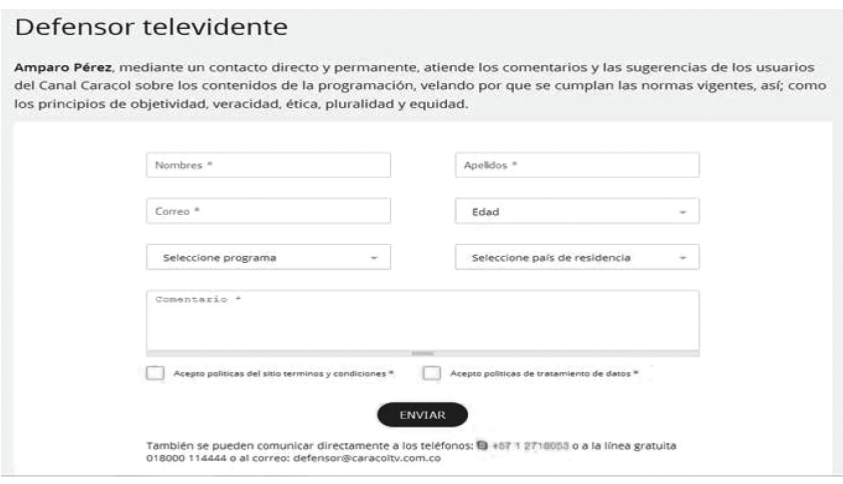

Figura 5. Doble vía

Fuente: tomado de Canal Caracol (http://www.caracoltv.com/defensordeltelevidente)

6 Aparecen simultáneamente datos para contactarse con el programa. 
Otro soporte consiste en la llamada telefónica. Su particularidad radica en que puede utilizarse tanto por el televidente como por el defensor, aunque ninguna de estas modalidades comparte el espacio-tiempo de transmisión del programa, ya que es grabada con anterioridad y luego expuesta en este (figura 6).

También están las páginas web y las redes sociales donde los televidentes tienen las mismas opciones de opinión.

Igualmente, la entrevista instaura una interacción no jerarquizada donde se busca registrar la posición del televidente a través de preguntas que le realiza el entrevistador/defensor. Consideremos que también se utiliza para con los responsables de los programas cuestionados y expertos. Puede ser de dos tipos: una en la que el entrevistado participa fuera de la transmisión en vivo (si el entrevistado es televidente aquí no hay respuesta a incógnitas). Observemos la transcripción \# $2^{8}$ :

\section{¿Sabe usted qué es la televisión digital terrestre?:}

13. A': e: la televisión digital terrestre?ll pues: es la que nosotros vemos? I usualmente? I esa no es así? Jaja.

15. $\mathrm{A}^{3}$ : pues yo entiendo que I mejora mucho la señal II que mejora mucho la señal y: Il y que funciona con un decodificador o: con un televisor a- I de acuerdo a la: II jajaa la tecnología nueva.
El segundo tipo ocurre cuando tanto entrevistado (sea televidente o experto) como defensor (entrevistador) discuten en la transmisión en vivo (aquí el defensor intenta dar respuesta al televidente). Para ilustrar se toman los siguientes fragmentos de la transcripción \# 1 donde el defensor entabla una entrevista con el periodista (J) de una sección de noticiero cuestionada:

62. D: ....aquí tengo una carta Juan Diego de una televidente Natalia Rey I que nos explic- escribió hace poco I diciendo que "en el noticiero hay un espacio que se llama el periodista soy yo I donde nosotros hacemos la denuncia I pero el noticiero no da soluciones I solo transmite I y me gustaría I que esto mejorara y que la noticia no se quede como un reportaje".

63. J: bueno I valdría la pena decirle a Natalialque nosotros no podemos hay que ser realista I responder $y$ atender absolutamente todas las denuncias y quejas I pero hay una cosa que sí llama la atención I y es que hacemos visible por lo menos I en un noticiero nacional I lo que de otra faroma- forma nunca se conocería I eso vale la pena rescatarlo por un lado I segundo en algunos casos si lo hacemos I no se puede en todos pero si en algunos concretos le voy a enumerar varios I primero I la estación de policía de Las Mercedes en Norte de Santander cuando los policías dormían en las aceras I eso I lo denunció un ciudadano a través del periodista soy yo y Noticias Caracol desplegó para nuestra siguiente emisión I todo un equipo periodístico I y terminaron naturalmente I dando respuesta las autoridades

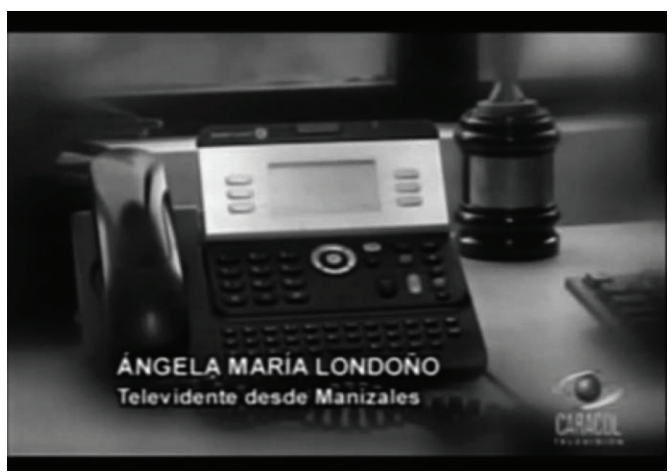

Figura 6.7 Llamada telefónica

Fuente: tomado de https://www.youtube.com/watch?v=eL7fFXaOaFE

7 Tomada de la emisión del 24 de abril de 2014.

8 Las diferentes $\mathbf{A}$ se refieren a los televidentes entrevistados. 
Ahora, en cuanto a los soportes se considera lo siguiente: estos los utilizan la mayoría de los programas del defensor analizados; con excepción del de la televisión y entrevista en estudio, los demás tienen por función recoger la posición del televidente, mas no resolver inmediatamente el debate, porque esto ocurre en la transmisión en vivo.

Un soporte innovador que solo utiliza el canal CityTV es la Citycápsula (figura 3), donde el televidente expone su opinión a través de una grabación audiovisual. Esta grabación la realiza la Citycápsula, especies de cámaras establecidas en lugares públicos, como rescata la transcripción \# 3 .

1. D: en un lugar en la ciudad donde rige la injusticia social y la malicia I llega un mecanismo para resolver las quejas e inquietudes de los televidentesllles: la Cápsula de la Justicia I busque cualquier Citycápsula y cuéntele lo bueno, lo malo y lo feo de CityTV I juzgue usted mismo y sea fiscal o defensor I en la Cápsula de la Justicia.

A continuación se amplía la situación de intercambio. Con ayuda de los soportes se puede reconocer que la situación de intercambio correspondiente en mayor parte es de orden monolocutivo, puesto que los temas a discutir, la organización formal, entre otros contenidos, están organizados de acuerdo con un otro que no está presente ni interviene en el espacio de comunicación simultáneamente; es decir, no hay co-presencia física de los participantes. Por consiguiente, el televidente expone su opinión pero es respondida en un tiempo posterior, así como también el defensor puede dar respuesta a la cuestión a muchos interlocutores acerca de un mismo tema en un tiempo y lugar diferente al de los televidentes. Algo claro es que cada interlocutor tiene una idea de ese otro. Aun así, también hay breves momentos de comunicación interlocutiva; por ejemplo, en el segundo tipo de entrevista el contenido de la comunicación se construye entre ambos interlocutores en interacción simultánea. En resumen, hay tres posibles momentos en la comunicación entre los interlocutores:
- Cuando interviene el televidente en ausencia del otro (monolocutiva).

- Cuando interviene el defensor en la transmisión del programa sin presencia directa o face-face con el otro (monolocutiva).

- Cuando interactúan de manera directa los dos interlocutores, comparten mismo tiempo-espacio, como es el caso de las entrevistas en vivo (interlocutiva).

\section{DISCURSO DEL DEFENSOR: ¿GÉNERO DISCURSIVO O SUBGÉNERO DISCURSIVO?}

Considerando que el género discursivo dentro del marco de la situación comunicativa se encuentra en la situación global, se observa que es posible hallar los subgéneros en la situación específica.

De esta manera, como ya se determinó, en el ámbito de práctica social mediática el género discursivo predominante es el género mediático. Por tanto, el programa del defensor del televidente es un subgénero del género del discurso mediático, por constituirse como una situación específica de este, caracterizada por sus particularidades de interacción, interlocutores, temáticas, como las ya expuestas anteriormente, las mismas que diferencian este subgénero de otras situaciones específicas como un noticiero televisivo o el reportaje que también forma parte del ámbito mediático.

También se evidencia que participan en el ámbito mediático otros subgéneros: la carta, la llamada, la entrevista, que nos refieren que la comunicación se puede instaurar de manera escrita y oral así como puede obedecer a un carácter formal o más cotidiano. Así, el subgénero mediático del defensor entra en interacción con otros géneros que les permiten generar la comunicación, pero esta combinación entre géneros se realiza, según Carranza (2012), en forma de alternancia, puesto que cada subgénero utilizado, a pesar de obedecer a los objetivos mediáticos, es fácilmente identificable. Es razonable entonces pensar lo siguiente: en la medida en que un subgénero es más utilizado que otro en una misma situación comunicativa, es 
posible determinar que en estos casos se puede hablar de géneros o subgéneros dominantes, para el caso lo constituye el programa del defensor del televidente; el uso de un género y subgénero sobre otro es una función que le corresponde al sujeto, pues es quien ante la diversidad de géneros puede elegir el más conveniente. Lo anterior ratifica la categoría de sujeto agente, que asumen los interlocutores.

\section{NIVEL DE LAS PROPIEDADES DISCURSIVAS Y NIVEL FORMAL}

A partir de los objetivos situaciones ya expuestos, aparecen los modos enunciativos que determinan comportamientos lingüísticos en cuanto a modos o formas de organizar el discurso, como lo descriptivo, lo narrativo y lo argumentativo (Charaudeau, 2012), cuya elección depende de las necesidades del sujeto.

El programa del defensor compone un discurso cuya linealidad es inicialmente explicativa, porque en aspectos más globales toma la siguiente secuencia (se analiza la transcripción \# 1): una primera etapa es contextualizar al televidente sobre el tema a discutir, esto consiste en presentarlo y dar a conocer información de apoyo:

74. P: el próximo 25 de octubre serán las elecciones I para alcaldes gobernadores I concejales I diputados I a las asambleas departamentales I y ediles a las juntas administradoras locales I y los medios de comunicación I tienen una gran responsabilidad en la información que den a los ciudadanos I para contribuir a que se elija a los mejores I en ese sentido Caracol Televisión I inició esta semana I su cubrimiento en Noticias Caracol.

En esta etapa ya se comienzan a involucrar secuencias de orden descriptivo al detallar el tema de discusión; en este caso, son las acciones de los medios frente a las campañas electorales. A continuación se da la descripción de la inquietud de un televidente:
75. P: el señor David Camargo I nos escribió pidiendo al canal I que se presenten las propuestas de los candidatos dice I "quisiera saber si Noticias Caracoll nos va a presentar las hojas de vida y las propuestas de los candidatos I que aspiran a los diferentes cargos I en las próximas elecciones regionales I teniendo en cuenta que en estas elecciones aspiran muchas personas investigadas y corruptas...".

Acto seguido actúa la explicación para definir la respuesta al televidente, y se recurre a la ejemplificación y descripción para profundizar el ejemplo, que en estos fragmentos es "la sección del dicho al hecho":

76. EF': vamos a hacer un cubrimiento muy completo del tema electoral en todo el país I vamos a hacer una sección que arrancó esta semana I que se Ilama Del Dicho al Hecho I y es I cómo aquellas cosas que prometen los candidatos I son realmente viables o no lo son I esto es I ser críticos también con las posturas...

A la par de estas secuencias algo claro es que el defensor del televidente permite confirmar posturas basadas en secuencias argumentativas, un primer ejemplo es la continuación del anterior fragmento, donde a partir de información con una base de autoridad, la Registraduría en este caso, se justifican las acciones del canal frente al proceso electoral.

77. D: según la Registraduría hay 14.936 aspirantes para estos cargos públicos I y por eso es muy: difícil que a todos los podamos ver por televisión I así que es necesario I que ustedes como ciudadanos I exijan a los candidatos de sus regiones los programas I de gobierno para que I a conciencia escojan el mejor

Otro ejemplo de las secuencias argumentativas la tiene muy marcada la Cápsula de la justicia, ya que toda la emisión se organiza ante un tema conductor y siempre se recurre a expertos para que justifiquen su pertinencia. De esta manera, la transcripción \# 2 consulta el defensor a expertos $(\mathbf{E})$ sobre la explicación y pertinencia de la TDT:

9 Entrevistado fuera de transmisión. 
1. D: ¿con qué objetivo se da el paso de la televisión análoga a la televisión digital terrestre?10

2. $\mathbf{E}^{\mathbf{1}}==$ obviamente es: es un objetivo que está enfocado I hacia un mejoramiento en la calidad del servicio de televisión I que en Colombia es un servicio público I por mandato constitucional I e: pero también tiene que ver con un ahorro y un uso eficiente del espectro electromagnético...

Al incorporar la metodología de las preguntas, el discurso de estos programas permite sustentar los puntos de vista (por ejemplo en el caso de los representantes de los programas cuestionados) y que los mismos representantes o expertos contribuyan a sustentar los argumentos.

Por otro lado, los televidentes aseguran sus posturas mediante el uso de secuencias de carácter explicativo (contextualizan el tema a cuestionar), descriptivo (especifican lo que censuran o elogian) y argumentativa, ya que su misma opinión siempre encierra una postura frente al tema. Por ejemplo, en el anexo 1, un televidente a través de su carta, se refiere al programa de Laura la santa colombiana, aclara su posición de elogio frente a los contenidos de este programa y especifica sus razones.

Por consiguiente, se observa cómo se concretan algunas cosas: lo primero es que tanto lo explicativo, lo descriptivo y lo argumentativo permiten buscar el principal fin de estos programas: atender las inquietudes de los televidentes, exponerlas, discutirlas y, por último, componer una respuesta satisfactoria para estos. Segundo, aquí la explicación se usa tanto para contextualizar como para responder al televidente del cómo se van a llevar a cabo ciertos procesos en la programación. Tercero, la descripción en el sentido en que especifica persiste en que las respuestas a los televidentes aseguren una mayor comprensión.

\section{CONCLUSIONES PRELIMINARES}

- En términos técnicos los programas del defensor del televidente, por su condición de

10 La pregunta aparece escrita en la pantalla y es enunciada. pertenecer a una cadena de programas televisivos, poseen cierta autonomía espacio-temporal que les permite establecer sus sistemas discursivos y formas de funcionamiento según sus necesidades.

- Además el defensor del televidente no solo es un espacio para que el televidente exponga y justifique su posición, sino también para que los diferentes representantes de programas justifiquen los contenidos de estos.

- El involucrar en la investigación el análisis de los soportes permitió evidenciar no solo las maneras de interacción entre los interlocutores (monolocutiva e interlocutiva), sino también las siguientes consideraciones: a) los programas del defensor comparten la mayoría de soportes, a excepción de la Citycápsula y la entrevista en estudio; b) a través del uso de estos soportes es posible que muchos temas adquieran un carácter polémico, ya que al integrar las opiniones del televidente, obliga a que el contenido de los programas sea debatido desde diferentes posturas y sean profundizados.

- Por otro lado, el análisis de los soportes permite ver cómo el defensor del televidente, aunque subgénero de lo mediático, involucra otros subgéneros, como la entrevista, la carta, la Ilamada. Teniendo en cuenta que el subgénero dominante es el del defensor, podemos ubicar el resto como soportes por el hecho de estar a la disposición del ámbito mediático y las intenciones del defensor. Con ello evidenciamos cómo otros subgéneros pierden características (formales, temáticas, etc.) al utilizarse en diferentes situaciones comunicativas particulares. Además, se rescata la necesidad de concebir al interlocutor como un sujeto agente.

- El carácter del comentario del televidente (queja, inquietud o sugerencia/elogio), será el factor que determine la organización discursiva en cuanto a los modos y la cantidad de los contenidos temáticos. Además: el 
programa puede referirse solo a un tema o a varios, y el punto de encuentro de la comunicación siempre tiende a discutir la programación televisiva.

La presencia de la figura del defensor, como se observó, no necesariamente lo encarna un locutor físico, también puede actuar como locutor cuya presencia únicamente sea la narración de la emisión.

En una siguiente fase de estudio se planea involucrar otras perspectivas al respecto, ya que aún quedan variantes que merecen análisis posterior, entre ellas la caracterización de las consecuencias de los horarios de estos programas, la población especial a la que se dirige y su efectividad en la opinión pública

\section{RECONOCIMIENTOS}

Esta investigación, acerca del género discursivo mediático en los programas del defensor del televidente, está inicialmente inscrita al proyecto de investigación del semillero Hermeneia, actualmente institucionalizado en la Universidad Distrital Francisco José de Caldas. Dicha investigación titulada "Los géneros discursivos en las interacciones cotidianas", a su vez, se encuentra acogida por una situación de financiación por parte del Centro de Investigación y Desarrollo Científico de la Universidad Distrital, en su Convocatoria \# 06 de 2015.

La investigación del género mediático participó, en octubre del año anterior, en el III Encuentro de Socialización de Experiencias Investigativas de la Facultad de Ciencias y Educación, con el título "El género discursivo mediático en los programas del defensor del televidente de la televisión nacional".

\section{REFERENCIAS BIBLIOGRÁFICAS}

Bajtin, M. (1982). Estética de la creación verbal. Buenos Aires: Siglo XXI.
Calderón, D.I. (2003). Género discursivo, discursividad y argumentación. Enunciación, 8(1), 44-56.

Calsamiglia B., H. y Tusón V., A. (2001). Las cosas del decir. Manual de análisis del discurso. Barcelona: Editorial Ariel.

Carranza, I. (2012). Los géneros en la vida social: la perspectiva fundada en las prácticas sociales. En: M. Shiro, P. Charaudeau y L. Granato. Los géneros discursivos desde múltiples perspectivas: teoría y análisis (pp. 99124). Madrid/Frankfurt: Iberoamericana/Vervuert.

Charaudeau, P. (2012). Los géneros: una perspectiva sociocomunicativa. En: M. Shiro, P. Charaudeau y L. Granato. Los géneros discursivos desde múltiples perspectivas: teoría y análisis (pp. 19-44). Madrid/ Frankfurt: Iberoamericana/Vervuert.

Kebrat-Orecchioni, C. (1986). La enunciación de la subjetividad en el lenguaje. Buenos Aires: Editorial Hachette.

Zerillo-Miriam, E. A. P. A.; Val-Marcela, C. A., y Moriena, C. S. (2012). Uso y mención del discurso de los medios de comunicación en la universidad. Proyecto de investigación. Departamento de Humanidades y Ciencias Sociales. Buenos Aires: Universidad Nacional de La Matanza.

\section{Anexos}

Anexo 1: (de la transcripción \# 1)

39. D: seguimos recibiendo cartas de felicitación por la producción Laura, la santa colombianal poco a poco los televidentes I están reconociendo la importancia de un producto I que no tiene nada que ver con la violencia del narcotráfico I algo que pedían a gritos los televidentes I dice el señor Alejandro Flores, de Medellínl"solo quería felicitarlos por la producción Lauralla cual me capturó I su producción impecable I el vestuario ni hablar I las locaciones y los actores I entre mil y mil cosas que se pueden ver I los felicito de corazón y que sean un ejemplo I para otras productoras I mil gracias por sus programas". 